\title{
The Role of QR Codes in FLT
}

\author{
${ }^{1}$ Leysan Shayakhmetova, ${ }^{2}$ Sholpan Zharkynbekova, ${ }^{3}$ Damira Akynova \\ ${ }^{1}$ Kazan Federal University, Kazan, Russian Federation \\ ${ }^{2,3}$ Gumilyov Eurasian National University, Nur-Sultan, Kazakhstan \\ Email:habirshah@mail.ru
}

Received: 23 ${ }^{\text {rd }}$ July 2019, Accepted: 10 $^{\text {th }}$ August 2019, Published: $31^{\text {st }}$ August 2019

\begin{abstract}
Modern education sets the task to prepare active and responsible graduates who will later be able to transform the life of his country in all its spheres. Teachers can only encourage this through the use of new and interesting teaching methods and educational technologies. The article shows the possibility of QR-codes as an interactive learning tool that can increase the interest and motivation of students. The task of this article is to examine the usage and the productiveness of implementing the QR codes. The application of QR technologies in the educational process will allow students to increase the interest in the educational process and the study of disciplines, get timely and full information to the student without the effect of waste. This technology will increase the availability of information, improve the quality of feedback during activities, improve their focus, and allow them to perform as close as possible to the interests of students. It is recommended to use scanners from well-known manufacturers, so that to be sure of its security and the absence of malware when going through unknown link. The survey was conducted among the students of Kostanay State Pedagogical University, and according to result we made a discussion.
\end{abstract}

Keywords

QR Codes, Education, Project Work, Information, Application.

\section{Introduction}

In today's modern world the rapid spread of mobile internet and portable devices have opened up many opportunities. At this stage, such an educational trend as Mobile learning is actively developing. Many studies are devoted to studying this problem $[1,2,3,4,5]$. The main task of a modern teacher in an educational institution is to help in the development of information competencies, and it is not only working with information, such as processing, search and translation from one to another, but also the ability to handle something new, universal. In order to accept this huge information we need computer technology. For the speed of information transfer came up with a QR-code.

The QR code is a form of 2D bar codes which was developed by Denso-Wave, a Japanese automatic data capture equipment company, in 1994. “QR" stands for "Quick Response.” It is readable by moderately equipped mobile phones with cameras and QR scanners [6; 8].

According to QRStuff.com research, USA, UK, China, Australia and Canada made up the top 5 QR code user countries' around the world. Initially they recorded scans from 235 countries during 2017 year [7; 6]. It is undeniable that QR-codes have appeared about 700 buses in our city Nur-Sultan. Generally, there are more than 900 buses on the city line. QrStuff.com researchers claim that majority of people use this bar code for PDF, Dropbox and for downloading educational materials. It is clear from these observations that QR codes not only effect in our social life, but also they impact in our educational system too.

\section{Scans By Device Operating System - 2017}

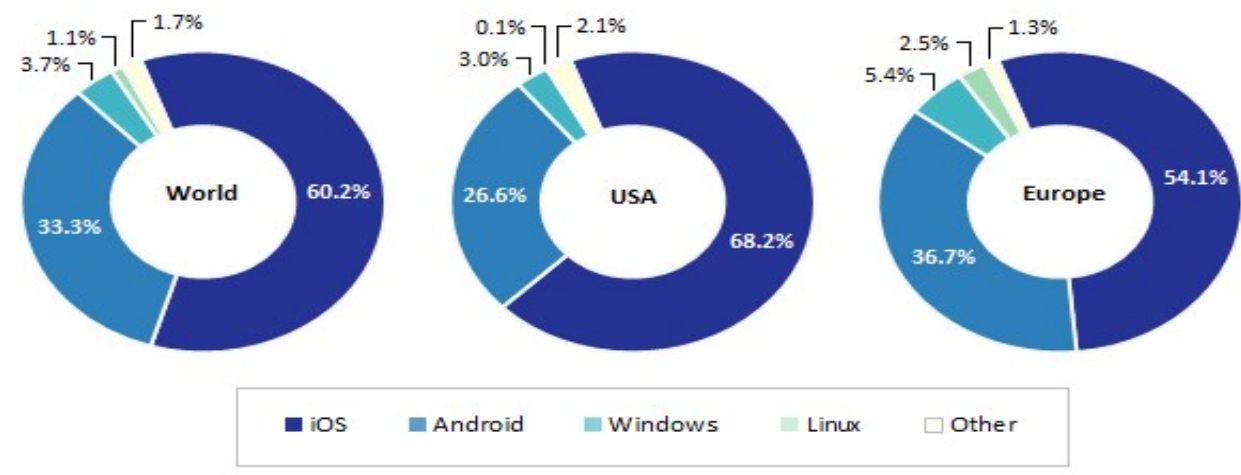

Figure 1: The Statistics of QR Code Usage around the World [2]

In the theory of Rogers 'innovation' defined as an idea, an application or an object considered to be new by an individual or organization [8]. A number of key issues arise from the statement. For instance, QR codes are going to be an 'innovation' tool in education platform in our technology world. By relying Rogers' model, the acceptance of 
barcodes may simply explained (see Figure 2). This model consists of five elements, which are like a chain will effetely impact by the law cause and effect. These elements are knowledge, persuasion, decision, implementation and confirmation.

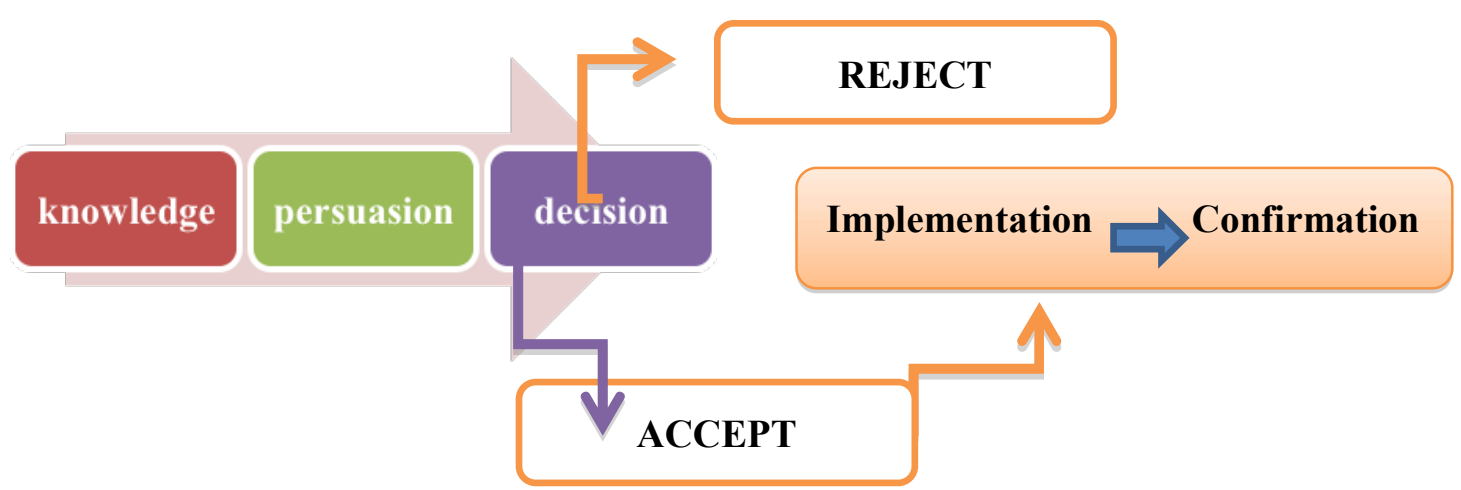

Figure 2: The Implementation Model of QR Codes in Education

These smart codes fully meet the modern requirements for obtaining and disseminating information, making this process convenient, operational and interactive. Using codes in education for various types of information, firstly, can help teachers, both in term and in extracurricular activities; secondly, it will lead to attracting the attention of students, to drag greater interest in comparison with traditional forms of education and will increase their motivation.

To test the efficiency and productiveness of implementing QR codes in project work, we recently conducted an experiment on second grade bachelor students of Kostanay State Pedagogical University. In an experimental study conducted on the use of $\mathrm{QR}$ codes in education, the views of 76 learners were determined.

\section{Methods}

In teaching English, the project method can be used in close contact with the curriculum. It should be noted that the theme of the project should not only be included in the overall context of language learning, but also be interesting enough for students. The choice of the theme of project work is very important, in the end, can determine the success and effectiveness of project work in General. For ourselves, we have determined it is important not only to formulate the theme, but also the ultimate goal of the project. Studying one of the sections of the textbook, which is called "Media and Movies", 2 grade bachelor students decided to create their own fairy tale book, and then they chose the cartoon "Aladdin" which is served as topic of the fairy tale animated book.

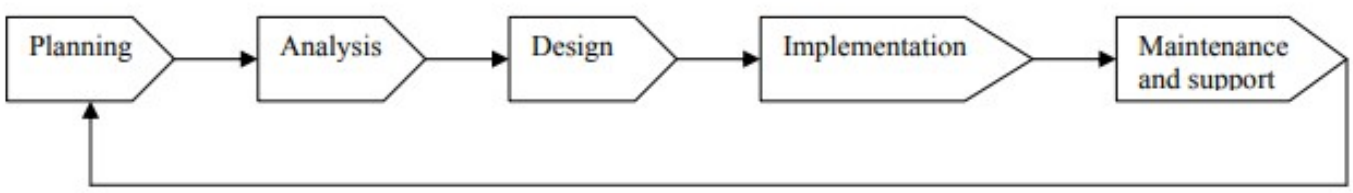

Figure 3: Stages of Project Work.

The second stage of the work involved the availability of output information on the project, finding the cartoon, watching it in English language, analyzing the cartoon, dividing into several parts and then making short videos to upload on YouTube channel, in case to easy link these videos to our codes.

While the project work, the students practiced how to work with QR code program and how to create their own codes. Firstly, we have conducted a pre-working survey, in order to know students knowledge about this program. The survey consisted with simple 5 questions:

1. Have you ever seen a QR code?

2. If you have seen a QR code, have you ever used one?

3. Have you ever used a barcode scanning application?

4. What did you use a QR code for?

5. Where students may use scanning QR codes?

At the end of the project we conducted post-working questions:

1. Did the QR Code support the project in positive influence or not?

What problems did you have while using the QR Codes in project work? 


\section{Results and Discussion}

I stage: Pre-working Conducted Survey

About two-thirds of our respondents have shown these codes in different cities of our country. Surprisingly, both men and women equally answered for the first question.

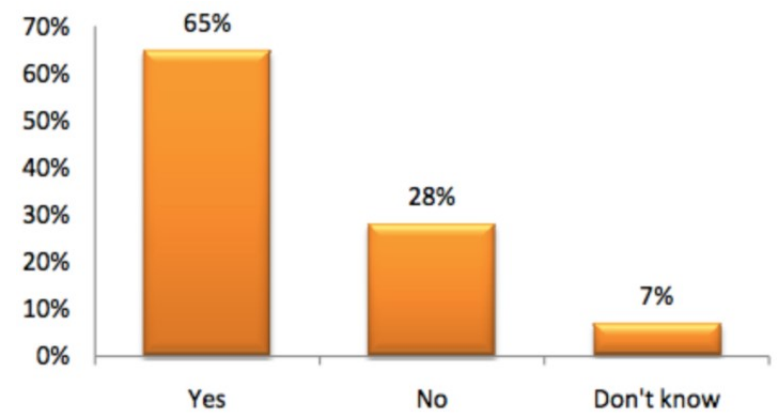

For the second question, half students who saw the QR codes, actually they used it for paying, exchanging or downloading study materials.

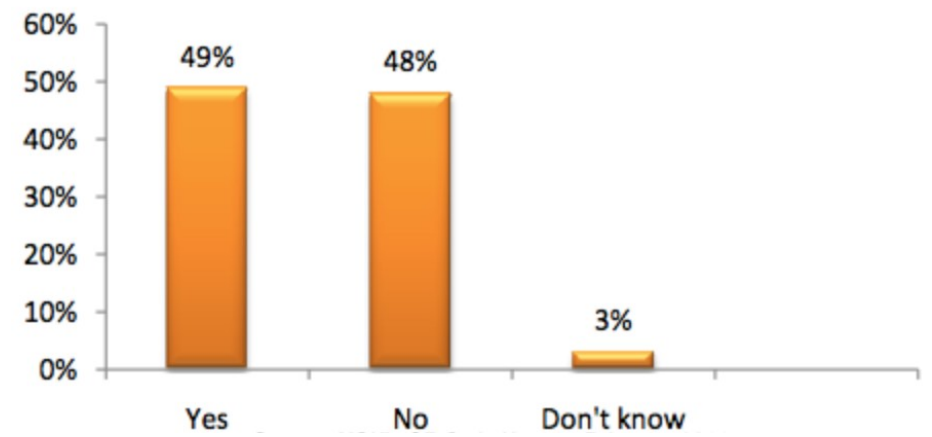

QR code usage varies by the type of certain smartphone and in this question Android program took 1 place.

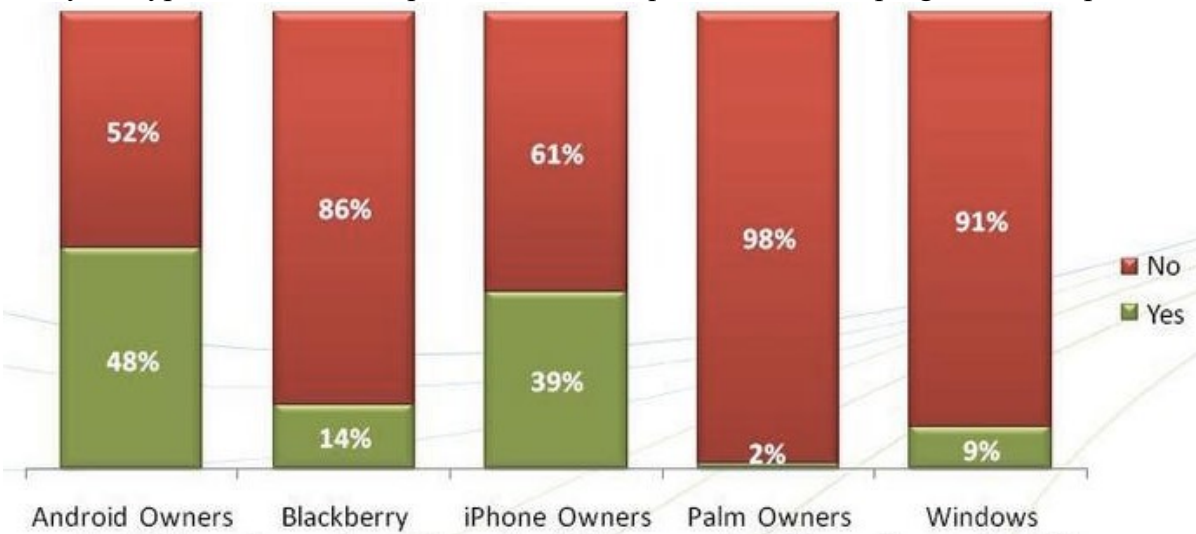

These smart codes used for different situation and for various productions. For instance, in Technodom market, students to get the full information about the typical product they used special programs. And a few students used for paying purpose.

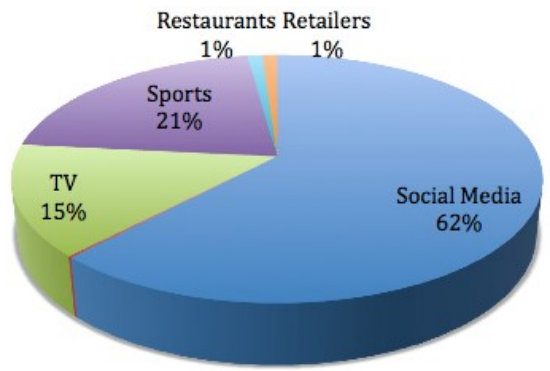


II Stage: Post-Working Survey Results

Second stage survey was conducted only with the students who participated to the project. (15 students) The participants were asked about if using QR Codes for education had positive effect on project work. The findings are presented in the Table below.

\begin{tabular}{|l|l|}
\hline Themes & Frequency \\
\hline No positive effect on learning & - \\
Positive effect on learning & 15 \\
\hline Visuals & 9 \\
Ease of use & 5 \\
Direct leading & 8 \\
Attractiveness & 9 \\
Updatable information resource & 5 \\
\hline
\end{tabular}

Table 1: The Feedback from the Survey

When students tested the QR code application, they clearly write about the factors and problems which they had while the project. (see Table 2)

\begin{tabular}{|l|c|}
\hline \multicolumn{1}{|c|}{ Themes } & Frequency \\
\hline Difficulties in technical problems in the process of transition to new technologies & 5 \\
Preference of different technologies & 10 \\
Lack of necessary equipment & 2 \\
Need for technological knowledge & 8 \\
\hline
\end{tabular}

\section{Table 2: The Feedback from the Survey}

As we can see, after the project work students liked this program and they actively started to use it in everyday life. The findings show us the importance of technological knowledge when applying into learning process. We need also academic staff who can guide students and help them with technical issues.

This study aimed at identifying the views of the participants about the QR Code project based learning. The results revealed that the participants achieved unanimity on the positive effects of QR Code on learning process. This result could be explained with the theory of the spread of innovation apps. According to the theory of innovations, through five stages of the theory, students got familiar about what are QR, they developed creativity and critical thinking skills, and accepted the innovational app, project product that implemented by using the QR Codes and they were completely satisfied with the results of the project.

It was found out that majority of the participants were aware of QR Codes. Use of QR Codes in education was considered to be an effective tool for PBL. This result proves the answers of participants (65\%-response of 'YES' to the question of "Have you ever seen a QR Code before") in the conducted questionnaire. The participants' responses on the usage of the barcodes in the first stage of conducted questionnaire showed that mostly students use these codes in the sphere of ads, internet cashes and market places, and as the result of after conducted survey, this were changed to educational materials after the usage of QR codes in the English lessons.

The participants agreed that the QR Code application should be used for PBL lessons as a tool for creativity and critical thinking. The main factor preventing the use of QR Codes is the need for enough technological knowledge to install and use the application. Other factors can be summarized as difficulties in transition to a new technology, lack of academic staff who knows how to use QR Codes, and lack of necessary hardware.

According to Rogers's five stage of innovation, students decided to accept this technology while working on project in the stage of discussion. It is possible to say that the learners who had reviewed the QR Code supported PBL lesson unit experienced the confirmation phase, which can be shown as an effective result of application QR codes in education system.

\section{Summary}

The QR code based project work experiment was successful. It enriched the traditional teaching methods and classroom learning and indicated that, with the QR codes, it is possible to arrange motivating and meaningful activities for students. At their best, QR codes can expand the learning experience and provide authentic tasks that take place in realworld settings.

QR-code is not some, as they say now, "trend", and has been used for quite a long period of time. It is simple and easy to use, and the number of methods of application is limitless, as already mentioned, it all depends on the imagination of man. As for education, it is a very effective method of involving students in educational and cognitive activities, because the 21 st century is the age of high information technology and most people have any means that to read this code in a matter of seconds and get detailed information about certain product or about some educational and cognitive task.

The obtained experience of using the proposed technology has shown their feasibility and effectiveness in modern realizable educational practice. At the same time, English language training is included not only in the system of lessons, but also implemented in the form of independent and playful activities, which is very important for the successful development of a foreign language. 
Thus, lessons using QR-code is a good opportunity to organize and conduct an innovative lesson:

$\checkmark \quad$ increases the effectiveness of training (development of students ' intelligence and skills of independent work in search of information; a variety of forms of educational activity);

$\checkmark \quad$ increases the student's interest in the subject and in teaching in general, improves the quality of education, activates the creative potential of the student and the teacher;

$\checkmark \quad$ carries out individual and differentiated approaches in training;

$\checkmark \quad$ provides flexibility in managing the learning process;

$\checkmark \quad$ improves the quality and diversity of knowledge controls;

$\checkmark \quad$ expands the volume of the presented educational information.

The use of smart technology, especially QR-code in the learning process opens up great opportunities for the teacher to use ICT in the classroom, Internet materials to work with students.

\section{Conclusions}

It should be noted that in the course of this work the students lost their fear of the English language, they learned its logical system better. This kind of work gives a lot of opportunities to apply the grammatical phenomena and structures. Students have a practical opportunity to use the knowledge and skills gained in lessons. It has been hypothesized that students had achieved the practical goal of the project and presents the product of this work in an informational website https://aruzhan-eskendir.wixsite.com/mysite-1.

Taking into account conducted surveys, it is obvious that using QR Codes on printed materials like course books may enhance the attractive aspects of printed materials and motivate students.

\section{Acknowledgements}

The work is performed according to the Russian Government Program of Competitive Growth of Kazan Federal University.

\section{References}

1. Mukharlyamova Liliya R. Mukhametzyanova Leilya, Shaiakhmetova Liliia, Shayakhmetova Leysan, Ashrapova Alsu. Internet technologies in Turkic languages training // Modern Journal of Language Teaching Methods. - 2016. - Special Issue, pp. 41-44.

2. Kuznetsova, Anastasia A.; Ilyasova, Lilia G.; Bezuglova, Olga A.; Cruz, Joaquin. Electronic educational resources in developing listening skills in elementary learners // REVISTA PUBLICANDO V: 5 Iss: 16. pp: $316-323$.

3. Bezuglova, Olga A.; Kuznetsova, Anastasia A.; Ilyasova, Liliya G. Monolingual electronic legal dictionaries: advantages and prospects // REVISTA PUBLICANDO. - V: 5 Iss: 16, pp: 63 - 69.

4. Ashrapova, Alsu; Zamaletdinov, Radif; Uderbaev, Almas; Zamaletdinova, Gulnara. Code Switching and Linguistic Identity // MODERN JOURNAL OF LANGUAGE TEACHING METHODS V: 8 Iss: 11 pp: 124 - 132.

5. Sjunina, Anastasiya; Yarmakeev, Iskander; Valiakhmetova, Nelly; Akhmadullina, Rimma. Webquest technology as a means of skill development of pedagogical tasks solving and students critical thinking // NATIONAL ACADEMY OF MANAGERIAL STAFF OF CULTURE AND ARTS HERALD V: 2 pp: $256-260$.

6. Law, Ching-yin and So, Simon (2010) "QR Codes in Education," Journal of Educational Technology Development and Exchange (JETDE): Vol. 3: Iss. 1, Article 7. DOI: 10.18785/jetde.0301.07.

7. 2017: QR Code Snapshot/ Posted: January 14th, 2018/ https://blog.qrstuff.com/2018/01/14/2017-qr-code-snapshot.

8. Rogers, M. E. (2003). Diffusion of innovation (5.ed.). New York: The Free Press. pp. 5-15.

9. Tulemissova, G., Bukenova, I., Korzhaspayev, A./ Sharing of teaching staff information via QR-code usage/ 2016/ Proceedings of the European Conference on IS Management and Evaluation, ECIME/SCOPUS.

10. Tulemissova, G./Mobile learning as a condition for the evolution of competencies in the alternative periods of study/ 2015/ Proceedings of the European Conference on e-Learning, ECEL/SCOPUS. 